\title{
Resposta da biomassa microbiana a diferentes corretivos de solo
}

Os microrganismos são importantes indicadores biológicos respondendo rapidamente às alterações desencadeadas por ações realizadas pelo homem. No Brasil, devido a característica ácida dos solos, realiza-se o processo de calagem visando o desenvolvimento adequado das culturas agrícolas. A neutralização da solução do solo pode influenciar a população microbiana e os processos por ela mediados. Assim, objetivou-se avaliar as alterações na população microbiana do solo ao longo do tempo desencadeadas pela aplicação de diferentes corretivos agrícolas. Para isso, foi coletado a camada superficial de um solo argiloso e através da necessidade de calagem aplicou-se os tratamentos: T1 - Testemunha; T2 - Calcário calcítico convencional; T3 - Se Power; T4 - Se Power Bio, com 4 repetições/tratamento. As amostras para análise microbiológica foram coletadas antes da aplicação dos tratamentos e aos 30,60 e 90 dias após aplicação. Foram pesadas $10 \mathrm{~g}$ de solo a cada $5 \mathrm{~cm}$ de profundidade e estas diluídas em série a 10-4 de onde foi retirada uma alíquota de 0,1 mL e disposta sob o meio BDA. A aplicação dos corretivos de solo proporcionou variação do $\mathrm{pH}$ do solo na camada de $0-5 \mathrm{~cm}$ durante o período avaliado, com valor máximo aos 30 dias após a aplicação. Ocorreram alterações tanto na população de bactérias quanto de fungos presentes nas amostras de solo em todas as profundidades e tratamentos avaliados. O tratamento com o produto Se Power Bio apresentou acréscimo diferencial na microbiota, possivelmente devido a existência de cepas bacterianas no mesmo, o que pode favorecer a sustentabilidade dos sistemas agroambientais de produção.

Palavras-chave: Acidez do solo; Calcário; Sustentabilidade.

\section{Action of different corrective in microbian soil biomass}

Microorganisms are important biological indicators, responding quickly to changes triggered by actions performed by man. In Brazil, due to a soil solution resource, perform the calibration process using the appropriate development of agricultural crops. The neutralization of the soil solution can influence a microbial population and the processes mediated by it. Thus, we aim to evaluate how changes in the soil microbial population over time triggered by the application of different agricultural assets. For this, a superficial layer of a clayey soil was collected and through the need for calibration applied to the following procedures: T1 - Control, T2 - Conventional calcite limestone; T3 - Se Power; T4 - Se Power Bio, with 4 repetitions/treatment. Samples for microbiological analysis were collected before the application of treatments and up to 30,60 and 90 days after application. $10 \mathrm{~g}$ of soil were weighed every $5 \mathrm{~cm}$ in depth and these were serially diluted to $10-4$ where a $0.1 \mathrm{ml}$ aliquot was taken and disassembled in BDA medium. The application of soil amendments provides soil pH variation in the $0-5 \mathrm{~cm}$ layer during the evaluated period, with a maximum value of 30 days after application. There were changes both in the population of bacteria and in fungi present in the amounts of soil at all depths and in the applied adjustments. Treatment with the product Se Power Bio shows a different performance in the microbiota, possibly due to the presence of bacterial bacteria that are not the same, which can favor the sustainability of agro-environmental production systems.

Keywords: Soil Acidity; Limestone; Sustainability.

Topic: Microbiologia Agrícola e Ambiental

Reviewed anonymously in the process of blind peer.
Received: 01/12/2020

Approved: 23/12/2020
Natalia Caetano Vasques (iD)

Universidade Estadual de Londrina, Brasil

http://lattes.cnpq.br/5359170763627832

http://orcid.org/0000-0002-7244-2954

natalia.caetanovasques@hotmail.com

\section{Bárbara Maria Lustri}

Centro de Ensino Superior de Maringá, Brasil

http://lattes.cnpq.br/9489628717027200

barbaramlustri@gmail.com

Thais de Oliveira lácono Ramari

Centro de Ensino Superior de Maringá

http://lattes.cnpq.br/8431394160883200

thaisiacono@yahoo.com.br

\author{
Francielli Gasparotto (iD) \\ Universidade Estadual de Maringá, Brasil \\ http://lattes.cnpq.br/2673470812353146 \\ http://orcid.org/0000-0002-4038-7364 \\ francipg@gmail.com
}

\section{Referencing this:}

VASQUES, N. C.; LUSTRI, B. M.; RAMARI, T. O. I.; GASPAROTTO, F.. Resposta da biomassa microbiana a diferentes corretivos de solo. Revista Ibero Americana de Ciências Ambientais, v.11, n.7, p.161169, 2020. DOI: http://doi.org/10.6008/CBPC2179$\underline{6858.2020 .007 .0015}$ 


\section{INTRODUÇÃO}

Os solos brasileiros, na sua maioria, apresentam acidez de média a alta (ZAMBROSI et al., 2014), isto é, o teor de íons de hidrogênio livres $(\mathrm{H}+)$ confere ao solo um potencial hidrogeniônico $(\mathrm{pH})$ baixo, sendo caracterizados por soluções ácidas. A importância deste atributo está estritamente relacionada à disponibilidade de nutrientes no solo, à influência no crescimento radicular e no desenvolvimento de microrganismos no solo (TAIZ et al., 2017). A acidez, constitui ainda, um dos maiores fatores resultantes de degradação dos solos em áreas extensivas nas zonas tropicais e temperadas (ZAMBROSI et al., 2014).

Para converter ou ausentar os possíveis danos gerados pela acidez do solo, emprega-se o uso de corretivos, no qual os íons de hidrogênio $(\mathrm{H}+)$ são equivalentemente substituídos, elevando a disponibilidade de alguns nutrientes, como o fósforo. Este fato promove o aproveitamento dos fertilizantes aplicados, bem como torna insolúvel outros elementos, como o alumínio (SOUZA et al., 2006). O incremento nos teores de cálcio $(\mathrm{Ca})$ e magnésio $(\mathrm{Mg})$ no solo também é consequência da aplicação de corretivos, porém sua eficiência está relacionada ao uso de dose adequada, das características dos produtos e uso da técnica de aplicação correta (PREZOTTI et al., 2013; GUARÇONI et al., 2017).

A calagem promove ainda o aumento da capacidade de troca catiônica (CTC) e disponibilidade de enxofre (S) e molibdênio (Mo), bem como liberação de fósforo (P) para absorção vegetal (MOREIRA et al., 2006), e consequentemente reduz gradualmente a disponibilidade de elementos tóxicos, como alumínio (Al) e manganês $(\mathrm{Mn})$ que afetam negativamente o crescimento das plantas e a reserva de matéria orgânica do solo (MAGALHÃES, 2018). O aumento da mineralização da matéria orgânica e beneficiamento da fixação simbiótica de nitrogênio também são influenciados de acordo com a aplicação de corretivos, já que são processos mediados por bactérias que são consideradas basófilas (MICHEREFF et al., 2005).

Além das características químicas e físicas citadas, a alteração do $\mathrm{pH}$ pode modificar de forma intensa a biomassa microbiana do solo (BMS), sua atividade e a relação bactéria/fungo. A BMS é considerada a parte viva e mais ativa do solo, sendo constituída principalmente por fungos e bactérias. A quantidade e a composição da BMS podem ser afetadas de acordo com a quantidade de material orgânico, aeração, umidade, temperatura, $\mathrm{pH}$, sistema de cultivo, adubação, rotação de culturas, textura do solo, entre outros (MOREIRA et al., 2006; KAMBLE et al., 2018).

De acordo com a faixa de $\mathrm{pH}$ do solo que os microrganismos se desenvolvem estes são classificados como basófilos; acidófilos; neutrófilos e; insensitivos ou indiferentes que toleram ampla faixa de $\mathrm{pH}$. Os fungos de forma geral são mais adaptados a desenvolverem em meios com pH mais baixo, em torno de 5,0 (acidófilos), enquanto as bactérias se desenvolvem melhor na faixa de pH entre 6,0 e 8,0 (neutrófilos e basófilos) (LEITE et al., 2007). De acordo com Moreira et al. (2006) o pH ácido ocasiona nas bactérias desnaturação proteica e enzimática, e afeta o crescimento de fungos micorrízicos pois eleva a disponibilidade de elementos tóxicos como o alumínio.

Desta forma, a BMS apresenta-se como um indicador biológico importante por sua capacidade em responder rapidamente às alterações no solo (KNUPP et al., 2011). Como estes microrganismos participam 
de diversos processos, como a formação do solo, decomposição de resíduos orgânicos, ciclagem de nutrientes, biorremediação, entre outros (REIS JÚNIOR et al., 2007), as alterações no pH do solo podem também influenciar nestes processos. Segundo Soong et al. (2020), os microrganismos são reconhecidos por sua habilidade em promover transformações bioquímicas dos nutrientes e por sua importância em prover os elementos nutritivos de interesse às plantas, principalmente $(\mathrm{N}, \mathrm{P}, \mathrm{S}, \mathrm{Zn}$ e $\mathrm{Cu})$. A biomassa microbiana ainda contribui no aspecto físico do perfil, tanto na colonização, quanto na decomposição da matéria orgânica do solo (MOS), os microrganismos contribuem para a estabilidade de agregados dos solos (LOURENTE et al., 2011).

De acordo com Ourives et al. (2010), cada grupo de microrganismos desempenha uma função no solo. A diversidade de microrganismos no solo é muito maior do que se imaginava e devido às alterações realizadas pelas práticas agrícolas, essa diversidade pode ser perdida antes mesmo de tornar-se conhecida (VAL-MORAES et al., 2009).

A preservação do pH ótimo, entre 6 e 7 (ARAÚJO, 2017) se faz necessária então tanto para desenvolvimento da biomassa microbiana quanto para o desenvolvimento da maioria das culturas de interesse do agronegócio brasileiro como a soja (SEIXAS et al., 2020), milho (CAIRES et al., 2004), feijão (SANTOS et al., 2017), citros (SACRAMENTO, 2013), entre outras.

Sendo assim, estudos para avaliação do desempenho de corretivos agrícolas por meio de neutralização de íons $\mathrm{H}+\mathrm{e}$ a correlação entre a variação do $\mathrm{pH}$ e a alteração da comunidade microbiana no solo mostraram-se relevantes para promoção dos sistemas provenientes de inúmeras funções que esses microrganismos desempenham no solo e então aplicação consciente de tais corretivos, acarretando sustentabilidade aos sistemas produtivos. Assim, objetivou-se avaliar as alterações na população microbiana do solo ao longo do tempo desencadeadas pela aplicação de diferentes corretivos agrícolas.

\section{MATERIAIS E MÉTODOS}

O experimento foi desenvolvido no laboratório de Microbiologia da Universidade Unicesumar, Maringá-PR. O delineamento experimental foi inteiramente casualizado (DIC) com 4 tratamentos: T1 Testemunha; T2 - Calcário Calcítico convencional (42\% CaO e 2\% MgO); T3 - Se Power (48\% CaO e 1,0\% MgO); T4 - Se Power Bio (48\% CaO e 1,0\% MgO + cepas bacterianas), com quatro repetições por tratamento e períodos de avaliação, sendo: antes da aplicação; 30; 60 e 90 dias após a aplicação dos tratamentos.

Para realização do experimento foi coletado, do município de Roncador - PR, a camada superficial (0$20 \mathrm{~cm}$ ) de um solo argiloso para composição das unidades experimentais e ainda uma amostra de 10g para primeira análise microbiológica, após a secagem. Cada unidade experimental foi composta por um cilindro de PVC (10 cm diâmetro e $20 \mathrm{~cm}$ altura) integrado com o referido solo, que após montagem completa da estrutura foi umedecido até a capacidade de campo e então aplicado superficialmente cada tratamento na dose para elevar a saturação de Ca a 65\% e Mg a 15\% na CTC. Desta forma, foi necessário 15,41 g do calcário calcítico convencional e 3,9 g do Se Power e Se Power Bio.

Aplicou-se então uma lâmina de água de $50 \mathrm{~mm}$ (quantidade $10 \mathrm{~mm}$ por hora) semanalmente. Após 
a passagem de água, de cada cilindro foram retiradas 4 amostras $(10 \mathrm{~g})$ a cada $5 \mathrm{~cm}$ de profundidade $(0-5 \mathrm{~cm}$; $5-10 \mathrm{~cm} ; 10-15 \mathrm{~cm} ; 15-20 \mathrm{~cm})$, sendo realizada a amostragem a cada 30 dias, para as análises microbiológicas e de $\mathrm{pH}$ em $\mathrm{CaCl}_{2}$. As amostras foram enviadas para análise no laboratório de Microbiologia da UNICESUMAR.

Para determinação do $\mathrm{pH}$ as mostras de solos foram secas ao ar, posteriormente moídas em moinho mecânico e peneiradas. Após a preparação tiveram o pH determinado em $\mathrm{CaCl}_{2}$ (EMBRAPA, 2011). Para determinação dos microrganismos procedeu-se a técnica de diluição em série para bactérias e fungos utilizando-se do meio BDA (batata-dextrose-ágar). Amostras de $10 \mathrm{~g}$ foram submetidas a secagem ao ar por 24 horas e então suspensas em $90 \mathrm{ml}$ de solução salina esterilizada. Após 30 minutos de agitação foram feitas diluições em série. De cada uma das diluições foi pipetada uma alíquota de 0,1 $\mathrm{mL}$ e depositada em placas de Petri, contendo o meio BDA para o isolamento de fungos e bactérias. As diluições utilizadas foram $10^{-3}$ para fungos e bactérias, com quatro placas de cada amostra.

As culturas foram incubadas no escuro, a temperatura constante de $28^{\circ} \mathrm{C}$, por três dias para bactérias e cinco dias para fungos, sendo o resultado expresso em número de unidades formadoras de colônia por contagem (UFC). Os resultados obtidos foram submetidos à análise de variância e as médias comparadas pelo teste de Scott-Knott a 5\% de significância, com auxílio do software estatístico Sisvar.

\section{RESULTADOS E DISCUSSÃO}

A aplicação dos corretivos acarretou aumento do pH das amostras de solo (T2, T3 e T4) nos primeiros $5 \mathrm{~cm}$ do solo, com valor máximo aos 30 dias após a aplicação, e então ocorreu o declínio destes valores até os 90 dias, onde chegaram próximos aos valores iniciais $(\mathrm{pH}=5,0)$. O tratamento que recebeu Se Power (48\% $\mathrm{CaO}$ e $1,0 \% \mathrm{MgO}$ ) foi o que apresentou maior elevação de $\mathrm{pH}$, diferindo significativamente dos demais tratamentos aos 30 dias após a aplicação (Gráfico 1). Porém, nas demais profundidades analisadas não houve variação significativa do $\mathrm{pH}$ entre os tratamentos avaliados.

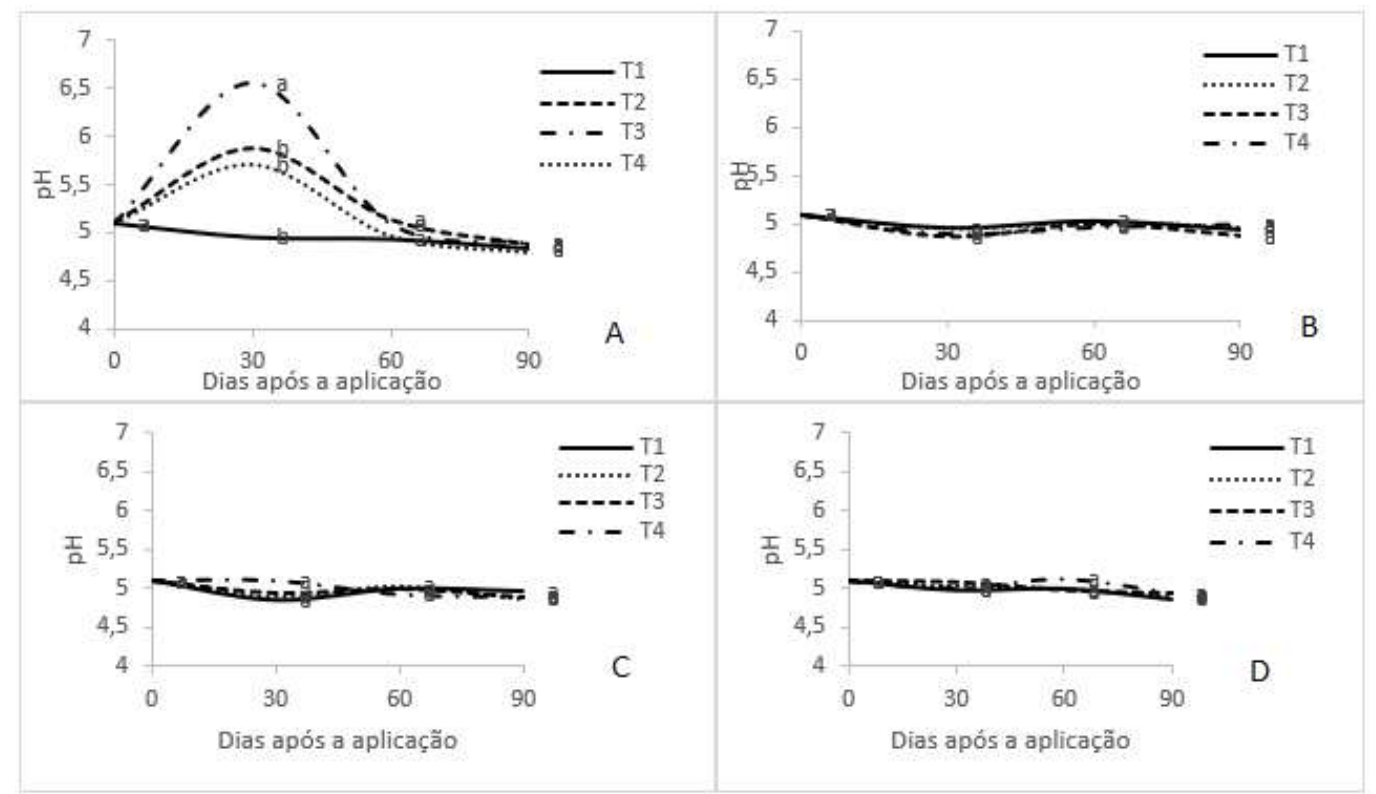

Gráfico 1: Valores médios de pH de amostras de solo submetidas a aplicação de diferentes corretivos. A) Profundidade de 0-5 $\mathrm{cm}$; B) Profundidade de 5-10 cm; C) Profundidade de 10-15 cm e D) Profundidade de 15-20 cm. T1 - Testemunha; T2 - Calcário Calcítico convencional (42\% CaO e 2\% $\mathrm{MgO})$; T3 - Se Power (48\% CaO e 1,0\% MgO); T4 - Se Power Bio (48\% CaO e 1,0\% MgO + cepas bacterianas). Mesmas letras no gráfico, não diferem entre si, pelo teste de Scott-Knott (5\%). 
Essa variação do $\mathrm{pH}$ na camada superficial dos solos pode favorecer alguns grupos de microrganismos. Schneider et al. (2011) avaliando o efeito de diferentes sistemas de manejo do solo associados ou não a calagem, verificaram que a aplicação do corretivo foi benéfica para os atributos de colonização micorrízica e comprimento de micélio extrarradicular, sendo mais significativa no plantio direto.

Quanto a influência de cada tratamento, sob a microbiota, na camada superficial $(0-5 \mathrm{~cm})$, pôde-se observar que ocorreu uma redução na população de bactérias e fungos em todos os tratamentos aos 30 dias após a aplicação dos tratamentos (DAA). Esta redução foi menos significativa em T3 e T4, para bactérias e em T1 e T2 para fungos. Aos 60 DAA todos os tratamentos apresentaram um aumento de UFCB e aos 90 dias houve uma redução destes valores em todos os tratamentos (Tabela 1), destaca-se que a menor população bacteriana foi observada na testemunha (T1) aos 60 DAA e em T2 aos 60 DAA.

Tabela 1: Número de Unidades Formadoras de Colônias Bacterianas (UFCB) e fúngicas (UFCF) x $10^{4} / \mathrm{g}$ de solo (profundidade de $0-5 \mathrm{~cm}$ ).

\begin{tabular}{|c|c|c|c|c|c|c|c|c|}
\hline \multirow{2}{*}{ TRAT $^{2}$} & \multicolumn{2}{|l|}{ ODAA $^{1}$} & \multicolumn{2}{|l|}{30 DAA } & \multicolumn{2}{|l|}{60 DAA } & \multicolumn{2}{|c|}{90 DAA } \\
\hline & UFCB & UFCF & UFCB $^{3}$ & UFCF & UFCB & UFCF & UFCB & UFCF \\
\hline T1 & 7,25 & 1,75 & $4,00 b$ & $1,50 a$ & $8,00 d$ & $0,25 b$ & $5,50 c$ & $0,50 c$ \\
\hline $\mathrm{T} 2$ & 7,25 & 1,75 & $3,75 c$ & $1,00 \mathrm{~b}$ & $9,75 b$ & $0,25 b$ & $3,50 \mathrm{~d}$ & $0,00 d$ \\
\hline T3 & 7,25 & 1,75 & $6,75 a$ & $0,75 c$ & $11,00 a$ & $0,75 a$ & $7,25 b$ & $1,50 a$ \\
\hline T4 & 7,25 & 1,75 & $6,75 a$ & $0,30 \mathrm{~d}$ & $8,75 c$ & $0,00 c$ & $7,75 a$ & $0,75 b$ \\
\hline
\end{tabular}

${ }^{1}$ Dias Após Aplicação: Número de dias após aplicação dos tratamentos. ${ }^{2} \mathrm{~T} 1$ - Testemunha; T2 - Calcário Calcítico convencional (42\% $\mathrm{CaO}$ e $2 \% \mathrm{MgO}$ ); $\mathrm{T} 3$ - Se Power (48\% CaO e 1,0\% MgO); T4 - Se Power Bio (48\% CaO e 1,0\% MgO + cepas bacterianas). ${ }^{3} \mathrm{Médias}$ seguidas pela mesma letra, nas colunas, não diferem entre si, pelo teste de Scott-Knott (5\%).

Em relação ao número de UFCF presente nas amostras coletadas de $0-5 \mathrm{~cm}$ do solo, observou-se aos 30 DAA, reduções em todos os tratamentos, sendo mais significativa em T4 e T3, respectivamente. Aos 60 DAA número de UFCF manteve-se estável no T3, e sofreu redução nos demais. E aos 90 DAA o T3 apresentou um aumento significativo de UFCF. Esta variação na população pode estar relacionada as mudanças de pH sofridas nas amostras de solo (Tabela 2).

Tabela 2: Número de Unidades Formadoras de Colônias Bacterianas (UFCB) e fúngicas (UFCF) x $10^{4} / \mathrm{g}$ de solo (profundidade de $5-10 \mathrm{~cm}$ ).

\begin{tabular}{lllllllll}
\hline \multirow{2}{*}{ TRAT $^{2}$} & O DAA $^{\mathbf{1}}$ & \multicolumn{3}{c}{ 30 DAA } & & 60 DAA & & 90 DAA \\
\cline { 2 - 9 } & UFCB & UFCF & UFCB & UFCF & UFCB & UFCF & UFCB & UFCF \\
\hline T1 & 7,25 & 1,75 & $6,50 \mathrm{a}^{3}$ & $0,50 \mathrm{c}$ & $8,50 \mathrm{c}$ & $0,25 \mathrm{c}$ & $3,25 \mathrm{c}$ & $0,25 \mathrm{c}$ \\
T2 & 7,25 & 1,75 & $3,50 \mathrm{c}$ & $0,25 \mathrm{~d}$ & $9,25 \mathrm{~b}$ & $1,00 \mathrm{a}$ & $1,75 \mathrm{~d}$ & $4,25 \mathrm{a}$ \\
T3 & 7,25 & 1,75 & $3,25 \mathrm{~d}$ & $0,75 \mathrm{~b}$ & $13,00 \mathrm{a}$ & $0,00 \mathrm{~d}$ & $7,50 \mathrm{~b}$ & $0,25 \mathrm{c}$ \\
T4 & 7,25 & 1,75 & $5,75 \mathrm{~b}$ & $1,50 \mathrm{a}$ & $9,25 \mathrm{~b}$ & $0,50 \mathrm{~b}$ & $13,75 \mathrm{a}$ & $1,00 \mathrm{~b}$ \\
\hline
\end{tabular}

${ }^{1}$ Dias Após Aplicação: Número de dias após aplicação dos tratamentos. ${ }^{2} \mathrm{~T} 1$ - Testemunha; T2 - Calcário Calcítico convencional (42\% $\mathrm{CaO}$ e $2 \% \mathrm{MgO}$ ); T3 - Se Power (48\% CaO e 1,0\% MgO); T4 - Se Power Bio (48\% CaO e 1,0\% MgO + cepas bacterianas). ${ }^{3} \mathrm{Médias}$ seguidas pela mesma letra, nas colunas, não diferem entre si, pelo teste de Scott-Knott (5\%).

Na profundidade de $5-10 \mathrm{~cm}$, a variação do número de UFCB seguiu o mesmo padrão observado para a profundidade de $0-5 \mathrm{~cm}$, com reduções aos 30 dias para todos os tratamentos, seguido de aumento aos 60 DAA. Porém, as maiores reduções foram observadas em T3 e T4, aos 30 DAA, e em T1 os 60 DAA. No final do período experimental o tratamento 4 destacou-se dos demais apresentando $13,75 \times 10^{4} \mathrm{UFC} / \mathrm{g}$ de solo. A população de fungos também variou entre os tratamentos e o período de avaliação com reduções em relação a população inicial, com exceção do T2 aos 90DAA que apresentou um aumento significativo do número de colônias chegando a 4,25 UFC x 10\%/g de solo (Tabela 2). 
Tabela 3: Número de Unidades Formadoras de Colônias Bacterianas (UFCB) e fúngicas (UFCF) x $10^{4} / \mathrm{g}$ de solo (profundidade de 10-15 cm).

\begin{tabular}{|c|c|c|c|c|c|c|c|c|}
\hline \multirow{2}{*}{ TRAT $^{2}$} & \multicolumn{2}{|c|}{0 DAA $^{1}$} & \multicolumn{2}{|c|}{30 DAA } & \multicolumn{2}{|l|}{60 DAA } & \multicolumn{2}{|l|}{90 DAA } \\
\hline & UFCB & UFCF & UFCB & UFCF & UFCB & UFCF & UFCB & UFCF \\
\hline T1 & 7,25 & 1,75 & $5,25 a$ & $0,25 b$ & $4,75 d$ & $0,75 a$ & $4,50 c$ & $0,50 a$ \\
\hline T2 & 7,25 & 1,75 & $4,50 b$ & $0,75 a$ & $13,50 a$ & $0,00 b$ & $2,25 d$ & $0,00 c$ \\
\hline T3 & 7,25 & 1,75 & $4,00 \mathrm{c}$ & $0,75 a$ & $9,25 c$ & $0,00 b$ & $8,00 b$ & $0,25 b$ \\
\hline T4 & 7,25 & 1,75 & $3,50 d$ & $0,75 a$ & $10,75 b$ & $0,00 b$ & $33,00 a$ & $0,50 a$ \\
\hline
\end{tabular}

${ }^{1}$ Dias Após Aplicação: Número de dias após aplicação dos tratamentos. ${ }^{2} \mathrm{~T} 1$ - Testemunha; T2 - Calcário Calcítico convencional (42\% $\mathrm{CaO}$ e $2 \% \mathrm{MgO}$ ); $\mathrm{T} 3$ - Se Power (48\% CaO e 1,0\% MgO); T4 - Se Power Bio (48\% CaO e 1,0\% MgO + cepas bacterianas). ${ }^{3} \mathrm{Médias}$ seguidas pela mesma letra, nas colunas, não diferem entre si, pelo teste de Scott-Knott (5\%).

Nas profundidades de $10-15 \mathrm{~cm}$ e $15-20 \mathrm{~cm}$ o padrão de alteração para o número de UFCB também manteve o padrão com redução aos 30 dias seguida de elevação para T2, T3 e T4, aos 60 dias. Já aos 90 DAA os tratamentos com maior número de UFCB foram detectadas nos tratamentos T3 e T4 (Tabelas 3 e 4). Com exceção para o T2 aos 30 dias na profundidade de $15-20 \mathrm{~cm}$ que apresentou aumento da população bacteriana (Tabela 4).

Quanto ao número de colônias fúngicas na profundidade de $10-15 \mathrm{~cm}$, os tratamentos que receberam os corretivos apresentaram menor redução da população de fungos aos 30 DAA, porém aos 60 DAA nenhuma colônia fúngica foi detectada nestes tratamentos. E aos 90 DAA a população continua reduzida e o T2 não apresentou nenhuma colônia novamente (Tabela 3).

Tabela 4: Número de Unidades Formadoras de Colônias Bacterianas (UFCB) e fúngicas (UFCF) x $10^{4} / \mathrm{g}$ de solo (profundidade de $15-20 \mathrm{~cm}$ ).

\begin{tabular}{|c|c|c|c|c|c|c|c|c|}
\hline \multirow{2}{*}{ TRAT $^{2}$} & \multicolumn{2}{|c|}{$0 \mathrm{DAA}^{1}$} & \multicolumn{2}{|l|}{30 DAA } & \multicolumn{2}{|l|}{60 DAA } & \multicolumn{2}{|l|}{90 DAA } \\
\hline & UFCB & UFCF & UFCB & UFCF & UFCB & UFCF & UFCB & UFCF \\
\hline T1 & 7,25 & 1,75 & $4,25 b$ & $0,25 c$ & $6,50 \mathrm{~d}$ & $3,00 d$ & $5,00 \mathrm{c}$ & $0,00 b$ \\
\hline T2 & 7,25 & 1,75 & $23,00 a$ & $0,75 a$ & $10,25 c$ & $7,50 \mathrm{~b}$ & $3,50 \mathrm{~d}$ & $0,00 b$ \\
\hline T3 & 7,25 & 1,75 & $4,25 b$ & $0,25 c$ & $11,00 a$ & $3,75 c$ & $16,50 a$ & $0,50 a$ \\
\hline T4 & 7,25 & 1,75 & $2,50 c$ & $0,50 b$ & $10,50 \mathrm{~b}$ & $22,00 a$ & $13,25 b$ & $0,50 a$ \\
\hline
\end{tabular}

${ }^{1}$ Dias Após Aplicação: Número de dias após aplicação dos tratamentos. ${ }^{2} \mathrm{~T} 1$ - Testemunha; T2 - Calcário Calcítico convencional (42\% $\mathrm{CaO}$ e $2 \% \mathrm{MgO}$ ); T3 - Se Power (48\% CaO e 1,0\% MgO); T4 - Se Power Bio (48\% CaO e 1,0\% MgO + cepas bacterianas). ${ }^{3} \mathrm{Médias}$ seguidas pela mesma letra, nas colunas, não diferem entre si, pelo teste de Scott-Knott (5\%).

Já na camada de 15-20 cm observou-se redução do número de UFCF em todos os tratamentos, seguida de aumento aos 60 DDA, com destaque para o T4 que apresentou 22 UFC $\times 10^{4} / g$ de solo. E aos 90 DDA ocorreu novamente reduções em todos os tratamentos. De acordo com Campos et al. (2017) a população de fungos e actinomicetos pode apresentar mudanças devido a condições de pH do solo. Isso pode ser justificado pela existência de diferentes classes microbiológicas na qual o crescimento pode ser favorecido ou desfavorecido devido a acidez do meio (LEITE et al., 2007).

De acordo com Moreira et al. (2006) bactérias se adaptam mais facilmente a ambientes menos ácidos do que fungos, este fato pode estar relacionado a menor redução da população bacteriana nas condições deste experimento. Caires et al. (1998) e Silva et al. (1997) ainda explicam que a ação do calcário superficialmente (até $10 \mathrm{~cm}$ de profundidade), tanto para correção do $\mathrm{pH}$ como para disponibilização de nutrientes, ocorre rapidamente, enquanto que em camadas subsuperficiais pode levar até trinta e dois meses para ação efetiva. Barbosa Filho et al. (2005) também afirmam que a ação corretiva realizada devido a prática da calagem é mais acentuada e pode ser observada de forma instantânea na camada de $0-10 \mathrm{~cm}$ de solo, fato este que pôde ser observado na variação do número de colônias de acordo com a passagem do tempo após 
aplicação dos produtos.

De acordo com Raaijmakers et al. (2009) e Berendsen et al. (2012) o solo pode ser caracterizado como um sistema dinâmico e biológico, no entanto Moreira et al. (2006) e Duchicela et al. (2013) afirmam que dentro deste dinamismo há a existência de micro-habitats que variam devido características físicas e químicas, como o pH. Desta maneira, pode-se explicar a variação entre os tratamentos, já que cada um se mostrou mais eficiente em algum momento da pesquisa, no entanto o tratamento que se mostrou com a maior média no número de unidades formadoras de colônias - tanto fúngicas quanto bacterianas - por mais vezes, foi o tratamento que recebeu a aplicação do Se Power Bio (T4), produto este caracterizado por possuir um conjunto de cepas de bactérias, que por sua vez se mostraram favoráveis para o desenvolvimento e reprodução da microbiota no meio desde o momento da aplicação do produto.

A diferença da disponibilidade de nutrientes no decorrer do solo é outro fator que pode estar relacionado à variação do número de unidades formadoras de colônias visualizadas nas análises. Chamados de 'hot spots' as zonas que possuem maior atividade microbiana, muitas vezes pela presença de matéria orgânica ou rizosfera (PHILIPPOT et al., 2013). Desta forma, ressalta-se a importância do processo de calagem para disponibilidade de nutrientes (elevação da CTC) que serão utilizados para o desenvolvimento das plantas e promoção do crescimento de microrganismos.

Não se sabe exatamente o motivo do $\mathrm{pH}$ do solo influenciar diretamente no desenvolvimento microbiano, porém sabe-se que a diversidade e a funcionalidade da microbiota são afetadas por este fator (CARDOSO et al., 2016), desta forma, neste trabalho desenvolveu-se apenas a influência no número de UFC promovida pelos tratamentos, não levando em consideração a diferenciação, função, desenvolvimento e benefício gerado por tais colônias.

\section{CONCLUSÕES}

A aplicação dos corretivos de solo proporcionou variação do $\mathrm{pH}$ do solo na camada de $0-5 \mathrm{~cm}$ durante o período avaliado, com valor máximo aos 30 dias após a aplicação.

Ocorreram alterações tanto na população de bactérias quanto de fungos presentes nas amostras de solo em todas as profundidades e tratamentos avaliados.

O tratamento com o produto Se Power Bio apresentou acréscimo diferencial na microbiota, possivelmente devido a existência de cepas bacterianas no mesmo.

\section{REFERÊNCIAS}

ARAÚJO, W. C.. Influência da granulometria do calcário calcinado dolomítico no pH do solo. Monografia (Bacharelado em Engenharia Química) - Centro Universitário de Formiga, Belo Horizonte, 2017.

BERENDSEN, R. L.; PIETERSE, C. M. J.; BAKKER, P. A. H. M.. The rhizosphere microbiome and plant health. Trends in Plant Science, v.8, p.478-486, 2012. DOI:

http://doi.org/10.1016/j.tplants.2012.04.001

CAIRES, E. F.; CHUEIRI, W. A.; MADRUGA, E.; FIGUEIREDO, A.
Alterações de características químicas do solo e resposta da soja ao calcário e gesso aplicados na superfície em sistema de cultivo sem preparo do solo. Revista Brasileira de Ciência do Solo, v.22, n.1, p.27-34, 1998. Dol: http://doi.org/10.1590/S0100-06831998000100004

CAIRES, E. F.; KUSMAN, M. T.; BARTH, G.; GARBUIO, F. J.; PADILHA, J. M.. Alterações químicas do solo e resposta do milho à calagem e aplicação de gesso. Revista Brasileira de Ciência do Solo, v.28, n.1, 2004. DOI: http://doi.org/10.1590/S0100-06832004000100013 
CAMPOS, B. B.; MORAES, G. P.; GOMES, G. D.; BATISTA, N. A.. Indicadores físico-químicos e microbiológicos da qualidade do solo utilizado para viticultura em Santa Teresa, Espírito Santo. Revista Brasileira de Agropecuária Sustentável, v.7, n.2, p.52-59, 2017. DOI: http://doi.org/10.21206/rbas.v7i2.414

CARDOSO, E. J. B. N.; ADREOTE, F. D.. Microbiologia do solo. 2 ed. Piracicaba: ESALQ, 2016.

DUCHICELA, J.; SULLIVAN, T. S.; BONTTI, E.; BEVER, J. D.. Soil aggregate stability increase is strongly related to fungal community succession along an abandoned agricultural field chronosequence in the Bolivian Altiplano. Journal of Applied Microbiology, v.50, p.1266-1273, 2013. DOI: http://doi.org/10.1111/1365-2664.12130

BARBOSA FILHO, M. P.; FAGERIA, N. K.; ZIMMERMANN, F. P.. Atributos de fertilidade do solo e produtividade do feijoeiro e da soja influenciados pela calagem em superfície incorporada. Ciência e Agrotecnologia, v.29, n.3, p.507-514. DOI: http://dx.doi.org/10.1590/S1413-70542005000300001

EMBRAPA. Empresa Brasileira de Pesquisa Agropecuária. Manual de métodos de análise de solos. Rio de Janeiro: Embrapa Solos, 2011.

GUARÇONI, A.; ALVAREZ, V. V. H.; SOBREIRA, F. M.. Fundamentação teórica dos sistemas de amostragem de solo de acordo com a variabilidade de características químicas. Terra Latinoamericana, v.35, n.4, p.343-351, 2017.

KAMBLE, P. N.; BAATH, E.. Carbon and nitrogen amendments lead to differential growth of bacterial and fungal communities in a high-ph soil. Pedosphere, v.8, n.2, p.255260, 2018. DOI: http://doi.org/10.1016/S10020160(18)60014-1

KNUPP, A. M.; FERREIRA, E. P. B.. Eficiência da quantificação do carbono da biomassa microbiana por espectrofotometria comparada ao método titrimétrico. Revista Brasileira de Ciências Agrárias, v.6, n.4, p.588-595, 2011. DOI: http://doi.org/10.5039/agraria.v6i4a1071

LEITE, L. F. C.; ARAÚJO, A. S. F.. Ecologia microbiana do solo. Teresina: Embrapa Meio-Norte, 2007.

LOURENTE, E. R. P.; MERCANTE, F. M.; ALOVISI, A. M. T.; GOMES, C. F.; GASPARINI, A. S.; NUNES, C. M.. Atributos microbiológicos, químicos e físicos de solo sob diferentes sistemas de manejo e condições de cerrado. Pesquisa Agropecuária Tropical, v.41, n.1, p.20-28, 2011. DOI: http://doi.org/10.5216/pat.v41i1.8459

MAGALHÃES, A. C. M.. Adubação orgânica com base na taxa de mineralização de nutrientes do composto orgânico. Dissertação (Mestrado em Ciência do Solo) - Universidade Federal do Ceará, Fortaleza, 2018.

MICHEREFF, S. J.; ANDRADE, D. E. G. T.; MENEZES, $M$.. Ecologia e manejo de patógenos radiculares em solos tropicais. Pernambuco: UFRPE, 2005.

MOREIRA, F. M. S.; SIQUEIRA, J. O.. Microbiologia e bioquímica do solo. 2 ed. Lavras: UFLA, 2006.
OURIVES, O. E. A.; SOUZA, G. M.; TIRITAN, C. S.; SANTOS, D. H.. Fertilizante orgânico como fonte de fósforo no cultivo inicial de brachiária brizantha cv. Marandú. Pesquisa Agropecuária Tropical, Goiânia, v.40, n.2, p.126-132, 2010.

PREZOTTI, L. C.; GUARÇONI, A.. Guia de interpretação de análise de solo e foliar. Vitória: Incaper, 2013.

RAAIJMAKERS, J. M.; PAULITZ, T. C.; STEINBERG, C.; ALABOUVETTE, C. MOENNE-LOCCOZ, Y.. The rhizosphere: a playground and battlefield for soilborne pathogens and beneficial microorganism. Plant and Soil, v.2, p.341-361, 2009.

REIS JÚNIOR, F. B.; MENDES, I. C.. Biomassa microbiana do solo. Planaltina: Embrapa Cerrados, 2007.

SACRAMENTO, R. V. O.. Avaliação da fertilidade do solo e do estado nutricional dos pomares cítricos nos municípios de Muritiba e Governador Mangabeira-Bahia. Dissertação (Mestrado em Ciências Agrárias) - Universidade Federal da Bahia, Salvador, 2013.

SANTOS, L. A. C.; SILVA, D. M. P.; OLIVEIRA, I. A.; PEREIRA, C. E.; CAMPOS, M. C. C.. Crescimento de cultivares de feijãocaupi em solo de terra firme e várzea. Ambiência Guarapuava, v.13, n.1, p.261-270, 2017. DOI: http://doi.org/10.5935/ambiencia.2017.01.17nt

SCHNEIDER, J.; KLAUBERG FILHO, O.; FONTOURA, S. M. V.; ALVES, M. V.. Influência de diferentes sistemas de manejo e calagem em experimento de longa duração sobre fungos micorrízicos arbusculares. Ciência e Agrotecnologia, v.35, n.4, p.701-709, 2011. DOI: http://doi.org/10.1590/S1413$\underline{70542011000400008}$

SEIXAS, C. D. S.; NEUMAIER, N.; BALBINOT JUNIOR, A. A.; KRZYZANOWSKI, F. C.; LEITE, R. M. V. B. C.. Tecnologias de Produção de Soja. Londrina: Embrapa Soja, 2020.

SILVA, N.; VAN RAIJ, B.; CARVALHO, L. H. D.; BATAGLIA, O. C.; KONDO, J. I.. Efeitos do calcário e do gesso nas características químicas do solo e na cultura do algodão. Bragantia, v.56, n.2, p.389-401, 1997. DOI: http://doi.org/10.1590/S0006-87051997000200018

SOONG, J. L.; FUCHSLUEGER, L.; MARAÑON-JIMENEZ, S.; TORN, M. S.; JANSSENS, I. A.; PENUELAS, J.; RICHTER, A.. Microbial carbon limitation - the need for integrating microorganisms into our understanding of ecosystem carbon cycling. Global Change Biology, v.26, n.4, p.1953-1961, 2020. DOI: http://doi.org/10.1111/GCB.14962

SOUZA, R. F.; FAQUIN, V.; ROGÉRIO, P.; TORRES, F.; BALIZA, D. P.. Calagem e adubação orgânica: influência na adsorção de fósforo em solos. Revista Brasileira de Ciência do Solo, v.30, n.6, p.975-983, 2006. DOI: http://dx.doi.org/10.1590/S0100-06832006000600007

TAIZ, L.; ZEIGER, E.; MOLLER, I. M.; MURPHY, A.. Fisiologia e desenvolvimento vegetal. Artmed Editora, 2017. 858 p.

VAL-MORAES, S. P.; VALARINI, M. J.; GHINI, R.; LEMOS, E. G. M.; CARARETO-ALVES, L. M.. Diversidade de bactérias de solo sob vegetação natural e cultivo de Hortaliças. Revista Ciência Agronômica, v.40, n.1, p.7-16, 2009. 
ZAMBROSI, F. C. B.; CANTARELLA, H.; RAIJ, B. V.. Critérios para calagem e adubação. In: AGUIAR, A. T. E.; GONÇALVES, C.; PATERNIANI, M. E. A. G. Z.; TUCCI, M. L. S.; CASTRO, C. E.
F.. Boletim 200: Instruções agrícolas para as principais culturas econômicas. Campinas: Instituto Agronômico, 2014. p.421-426.

A CBPC - Companhia Brasileira de Produção Científica (CNPJ: 11.221.422/0001-03) detém os direitos materiais desta publicação. Os direitos referem-se à publicação do trabalho em qualquer parte do mundo, incluindo os direitos às renovações, expansões e disseminações da contribuição, bem como outros direitos subsidiários. Todos os trabalhos publicados eletronicamente poderão posteriormente ser publicados em coletâneas impressas sob coordenação da Sustenere Publishing, da Companhia Brasileira de Produção Científica e seus parceiros autorizados. Os (as) autores (as) preservam os direitos autorais, mas não têm permissão para a publicação da contribuição em outro meio, impresso ou digital, em português ou em tradução. 